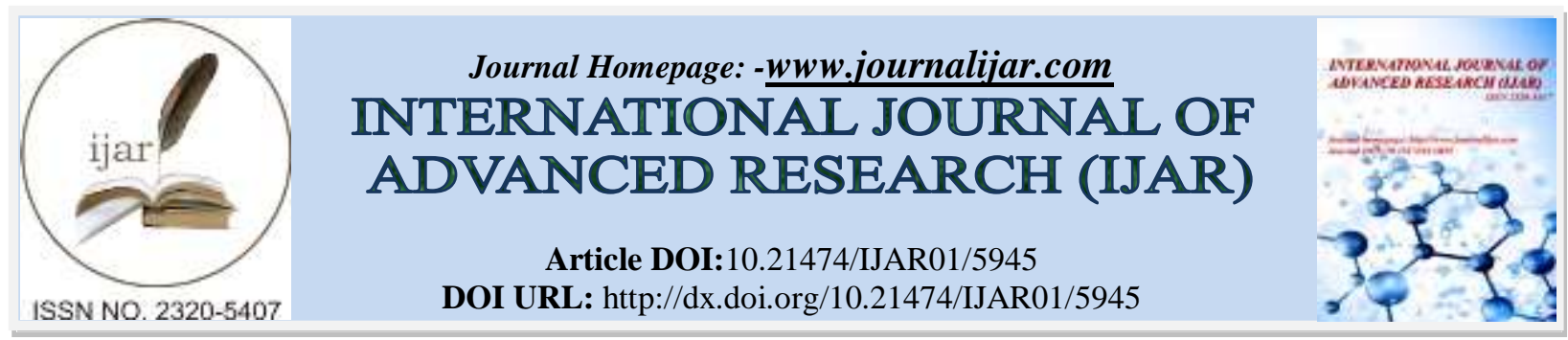

RESEARCH ARTICLE

\title{
THYROID STIMULATING HORMONE (TSH) SECRETING PITUITARY ADENOMA: A RARE CAUSE OF THYROTOXICOSIS.
}

\author{
Santosh B ${ }^{1}$, Anandh Balasubramaniam ${ }^{2}$, Raman Boddula ${ }^{3}$, Aditya Hegde ${ }^{1}$, Chimutai Chinte ${ }^{1}$, Ashok \\ Venkatanarasu ${ }^{3}$ and Milap Shah ${ }^{4}$. \\ 1. Resident, Department of Endocrinology, Yashoda Hospital, Secunderabad. \\ 2. Senior Consultant, Department of Neurosurgery, Yashoda Hospital, Secunderabad. \\ 3. Senior Consultant, Department of Endocrinology, Yashoda Hospital, Secunderabad. \\ 4. Senior Consultant, Department of Pathology, Yashoda Hospital, Secunderabad.
}

\section{Manuscript Info}

Manuscript History

Received: 02 October 2017

Final Accepted: 04 November 2017

Published: December 2017

Key words:-

TSHoma, TSH/LHoma, Thyrotoxicosis, TSH secreting Pituitary adenoma, Octreotide.

Corresponding Author:-Santosh B.

Address:-Resident, Department of Endocrinology, Yashoda Hospital, Secunderabad.

\section{Abstract}

Introduction: Thyroid stimulating hormone secreting pituitary adenoma (TSHoma) is a rare cause of thyrotoxicosis, which manifests with features of thyrotoxicosis along with neurological manifestations of pituitary tumour. Biochemically, it is characterized by elevated thyroid hormone (T3 and T4) levels with unsuppressed TSH levels. It accounts for $1-2 \%$ of all pituitary adenomas. Mixed TSHomas account for $30 \%$ of these cases, among which mixed TSHoma/LH(luteinizing hormone)oma is very rare $(<2 \%)$. We report a case of mixed TSHoma/LHoma, who was successfully treated with pre-operative Somatostatin analogues followed by Endoscopic Transphenoidal surgery for resection of pituitary adenoma.

Case report: A 35 years old, male presented to our hospital in September 2017 with complaints of headache, decreased vision in both eyes, palpitations, excessive sweating, tremors of the hands and increased frequency of loose stools since 8 months. He had bilateral gynaecomastia and decreased libido since 6 months. On evaluation, he was found to have Free T3: $7.5 \mathrm{pg} / \mathrm{ml}(1.45-3.48)$, Free T4: $2.1 \mathrm{ng} / \mathrm{dl}$ (0.75-1.85), TSH: $25.31 \mathrm{mU} / 1$ (0.27-4.2), Prolactin: $31 \mathrm{ng} / \mathrm{ml}$ (4.1-15.4). MRI Brain showed pituitary macroadenoma of size $2.7 \times 3.4 \times 3.6 \mathrm{~cm}$ with suprasellar extension and displacement of optic chaisma laterally. He was treated initially with daily subcutaneous Octreotide for 2 months followed by a single dose of long acting Octreotide LAR. One week after starting Octreotide, his symptoms improved and Free T3 was decreased to $5.42 \mathrm{pg} / \mathrm{ml}$, Free T4 to $1.75 \mathrm{ng} / \mathrm{dl}$ and TSH came down to $16.34 \mathrm{mU} / \mathrm{l}$. Then 2 months later, Free T3 was $1.7 \mathrm{pg} / \mathrm{ml}(2.1-4.2)$, Free $\mathrm{T} 4$ was $0.81 \mathrm{ng} / \mathrm{dl}(0.8-2.7)$, TSH was $0.98 \mathrm{mU} / \mathrm{l}(0.35-4.5)$. His $8 \mathrm{am}$ cortisol was $5.5 \mathrm{mcg} / \mathrm{dl}$, LH was $2.61 \mathrm{U} / \mathrm{l}$, FSH was $3.63 \mathrm{U} / \mathrm{l}$, Testosterone was $1.59 \mathrm{ng} / \mathrm{ml}$, IGF-1 was $149 \mathrm{ng} / \mathrm{ml}$ and Prolactin was $20.2 \mathrm{ng} / \mathrm{ml}$. USG neck showed normal sized thyroid gland with a tiny colloid cyst of size $5 \times 3 \mathrm{~mm}$ in the right lobe of thyroid. Repeat MRI Brain showed pituitary macroadenoma measuring $2.2 \times 2 \times 2.6 \mathrm{~cm}$ with suprasellar extension, displacing the optic chaisma superiorly and partial encasement of bilateral cavernous ICA. He was treated with 
Endoscopic Transphenoidal surgery for resection of pituitary adenoma, along with peri-operative steroid coverage and levothyroxine supplementation. Post-operative period was uneventful, his steroids were tapered and stopped. The histopathology and immunohistochemistry report were s/o TSHoma. He was discharged 1 week later with levothyroxine supplementation.

Conclusion:TSHoma should always be considered in patients who present with signs and symptoms of thyrotoxicosis, but with unsuppressed TSH levels in presence of elevated thyroid hormone levels, especially in those who have features of mass effects of pituitary tumour. Its recognition is important avoid unnecessary anti-thyroid drugs and thyroid ablative therapies, which can have a detrimental effect on the pituitary mass.

Copy Right, IJAR, 2017,. All rights reserved.

\section{Introduction:-}

TSHoma is a rare cause of thyrotoxicosis, which manifests with features of thyrotoxicosis along with neurological manifestations of pituitary tumour. Biochemically, it is characterized by elevated thyroid hormone (T3 and T4) levels with unsuppressed TSH levels. The important differential diagnosis for TSHoma is resistance to thyroid hormones (RTH). TSHomas contribute to $1-2 \%$ of all pituitary adenomas. Mixed TSHomas account for $30 \%$ of these cases, among which mixed TSHoma/LHoma is very rare $(<2 \%) .[1,2]$ We report a case of mixed TSHoma/LHoma, who was successfully treated with pre-operative Somatostatin analogues followed by Endoscopic Transphenoidal surgery for resection of pituitary adenoma.

\section{Case report:-}

A 35 years old, male presented with complaints of headache, decreased vision in both eyes, palpitations, excessive sweating, tremors of the hands and increased stool frequency since 8 months. He had bilateral gynaecomastia and decreased libido since 6 months. There was no significant family history.

On evaluation, his Free T3 was $7.5 \mathrm{pg} / \mathrm{ml}(1.45-3.48)$, Free T4 was $2.1 \mathrm{ng} / \mathrm{dl}(0.75-1.85)$, TSH was $25.31 \mathrm{mU} / \mathrm{l}(0.27$ 4.2), and Prolactin was $31 \mathrm{ng} / \mathrm{ml}$ (4.1-15.4). MRI Brain showed pituitary macroadenoma of size $2.7 \times 3.4 \times 3.6 \mathrm{~cm}$ with suprasellar extension.

He was treated initially with daily subcutaneous Octreotide (100mcg TID) for 2 months followed by single dose of long-acting Octreotide LAR 30mg. One week after starting Octreotide, his symptoms improved and Free T3 decreased to $5.42 \mathrm{pg} / \mathrm{ml}$, Free T4 to $1.75 \mathrm{ng} / \mathrm{dl}$ and TSH to $16.34 \mathrm{mU} / \mathrm{l}$. Then 2 months later, Free T3 was further reduced to $1.7 \mathrm{pg} / \mathrm{ml}$, Free T4 was $0.81 \mathrm{ng} / \mathrm{dl}$, and TSH was $0.98 \mathrm{mU} / \mathrm{l}$. His $8 \mathrm{am}$ cortisol was $5.5 \mathrm{mcg} / \mathrm{dl}$, LH was $2.61 \mathrm{U} / \mathrm{l}$, FSH was $3.63 \mathrm{U} / \mathrm{l}$, Testosterone was $1.59 \mathrm{ng} / \mathrm{ml}$, IGF-1 was $149 \mathrm{ng} / \mathrm{ml}$ and Prolactin was $20.2 \mathrm{ng} / \mathrm{ml}$. USG neck showed normal-sized thyroid gland with a tiny colloid cyst of size $5 \times 3 \mathrm{~mm}$ in the right lobe of thyroid. We repeated MRI Brain, which showed pituitary macroadenoma measuring $2.2 \times 2 \times 2.6 \mathrm{~cm}$ with suprasellar extension. The size of the pituitary adenoma had reduced by $60 \%$ following Octreotide treatment. He then underwent Endoscopic Transphenoidal surgery for resection of pituitary adenoma, along with peri-operative steroid coverage and levothyroxine supplements. We started levothyroxine to avoid peri-operative complications of low thyroid hormone levels. Post-operative period was uneventful; steroids were tapered and stopped. The histopathology report showed pituitary adenoma and immunohistochemistry staining showed $95 \%$ positivity for LH and $5 \%$ positivity for TSH. 8 days post-operatively, his Free T3 was $1.1 \mathrm{pg} / \mathrm{ml}$, Free T4 was $0.96 \mathrm{ng} / \mathrm{dl}$, TSH was $0.05 \mathrm{mU} / \mathrm{l}$, 8 am cortisol was $3.6 \mathrm{mcg} / \mathrm{dl}$ and Prolactin was $13.6 \mathrm{mcg} / \mathrm{dl}$.

The final diagnosis was made as Mixed TSH/LH producing pituitary macroadenoma (with LH being non-secreting component). He was discharged 1 week later with levothyroxine supplementation.

\section{Discussion:-}

TSHoma is a rare cause of thyrotoxicosis. It forms a part of syndrome of "Inappropriate Secretion of TSH" (IST), characterized by a nonsuppressed TSH in presence of high levels of thyroid hormones (T4 and T3). The other part being Resistance to Thyroid Hormones (RTH).[1,2] The first case of TSH-oma was documented in 1960 by 
measuring TSH with bioassay. In 1970, Hamilton reported a case of TSH-oma proved by RIA. Since then, about 400 cases have been described in the literature.[3]

They account for about $1-2 \%$ of all pituitary adenomas, with prevalence of one per million. TSH-omas can occur at any age, but are common in $3^{\text {rd }}-6^{\text {th }}$ decade with equal prevalence in both genders.[3]

Around $70 \%$ of TSHomas are pure TSH-producing, and remaining 30\% are mixed adenomas, among which association with GH (18\%) and prolactin $(10 \%)$ is commoner than FSH/LH $(<2 \%)$.[1]

Pathologically, they are often benign; transformation into carcinoma with metastasis is rare. Most are macroadenomas $(87 \%)$, and have high local invasiveness. Previous thyroid ablation either by surgery or radioiodine has deleterious effects on size and invasiveness of the tumor, probably due to complete loss of negative feedback caused by absence of the thyroid hormones. TSHomas are often fibrous, sometimes so hard that they have been referred to as pituitary stone.[3]Microscopically, they are chromophobic; but occasionally take basic or acid stain. Ultrastructurally, cells appear monomorphous. Immunostaining studies show the presence of TSH- $\beta$, either free or with $\alpha$ subunit; and few may have negative TSH- $\beta$ immunostaining.[3]

The etiology of TSHomas is not completely known. Few genetic studies have shown Pit-1 overexpression, absence of TR-alpha1/TR-beta1 expression and some show loss of heterozygosity of chromosome Ch.11q13.[1,3]

Most patients present with features of thyrotoxicosis like palpitations, increased sweating, weight loss, tremors, increased stool frequency, anxiety, etc. More than $90 \%$ patients have goiter. However, our patient had normal-sized thyroid gland, probably due to prior treatment with Octeotide, which is known to reduce goiter size.[4] 40\% patients may have headache and visual disturbances. Mixed TSHoma/GHoma can present with acromegaly. Mixed TSHoma/FSHoma/LHoma can present with menstrual disturbances and galactorrhoea. $[1,2,3]$

Biochemically, TSHomas have unsuppressed TSH levels in presence of elevated thyroid hormones. TSH levels in these patients can vary across a wide range from $0.5 \mathrm{mIU} / \mathrm{L}$ to $>500 \mathrm{mIU} / \mathrm{L}$. They have increased alpha-subunit levels and the alpha-subunit/TSH molar ratio is $>1$. Steroid hormone binding globulin (SHBG) and markers of bone resorption are higher in these patients; these are markers of peripheral action of thyroid hormones and they help in differentiating TSHomas from syndrome of RTH, in whom the levels are normal or low.[2,3]

The other methods for differentiating TSHoma and RTH is by dynamic testing. TSH stimulatory tests include: TRH test and Dopamine antagonists test, which show lack of stimulation of TSH secretion in TSHomas. TSH inhibitory tests include: Werner's test or T3 suppression (contraindicated in elderly or with coronary heart disease) and Octreotide test.[2,3,5] Different protocols using Octreotide have been described, which show reduction of TSH levels by 50\% from baseline in TSHomas.[5,6] We demonstrated more than 50\% inhibition of TSH levels with Octreotide treatment in our patient.

MRI is the common imaging modality used. Pituitary scintigraphy with radiolabeled Tyr3-substituted octreotide can also successfully image TSH-omas.[3]

The first line of treatment is to surgically remove or debulk the tumor by transsphenoidal or subfrontaladenomectomy. To restore euthyroidism before surgery, antithyroid drugs or Somatostatin analogs (e.g., Octreotide, Lanreotide) with Propranolol can be administered. If surgery is contraindicated or declined, stereotaxic radiotherapy and subsequent Somatostatin analogue administration is usually considered. Dopamine agonists have also been tried, but with mixed response.[2,3]

Different criteria have been proposed to define the cure following treatment, especially after pituitary surgery. However, suppressed TSH levels 1 week after surgery has good predictive value in defining cure.[2] We demonstrated cure in our patient, according to this criteria and the TSH levels 1 week post-operatively in our patient was suppressed $(0.05 \mathrm{mIU} / \mathrm{L})$.

Follow-up requires clinical and biochemical evaluation 2-3 times in the first year postoperatively and then annually. Pituitary imaging should be performed once in every 2-3 years, and whenever biochemical abnormality or clinical symptoms recur.[3] 


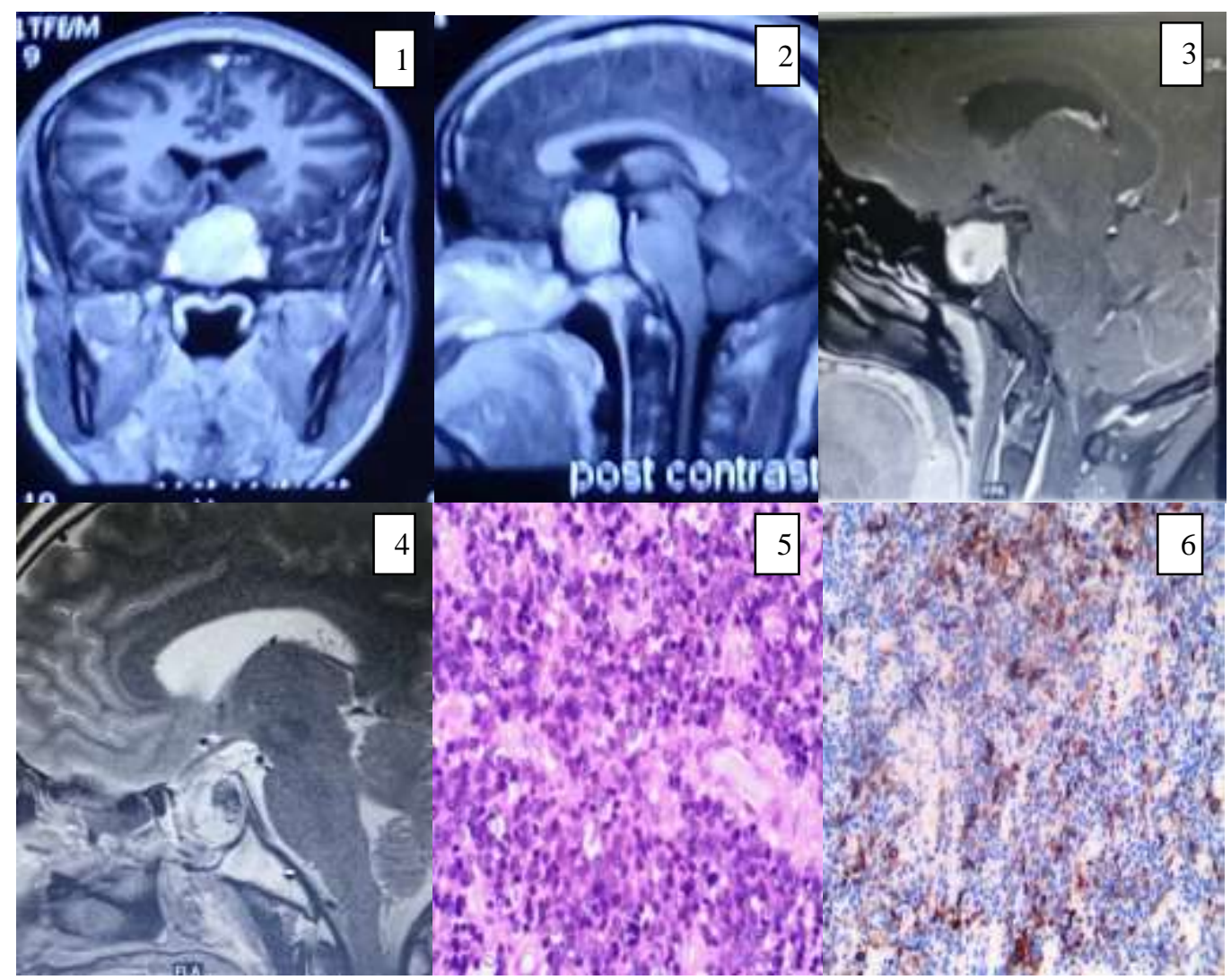

Figures: 1) and 2) Coronal and sagittal sections of MRI brain showing pituitary macroadenoma, before Octreotide therapy. 3) Sagittal section of MRI brain showing reduction in the size of pituitary macroadenoma, following Octreotide therapy. 4) Sagittal section of Post-operative MRI brain showing complete resection of the tumour and widening of sella due to fluid filled cavity, containing focal areas of haemorrhage and air. 5) Histopathology of the tumour showing monomorphous adenoma cells, and 6) Immunohistochemistry showing positive staining for TSH and LH.

\section{Conclusion:-}

TSHoma should be considered in patients who present with features of thyrotoxicosis, with unsuppressed TSH levels in presence of elevated thyroid hormone levels, especially those who have mass effects of pituitary tumour. Its recognition is very important because the treatment completely differs. It can be completely cured with excision of pituitary tumour. Thus, we can avoid unnecessary treatment with anti-thyroid drugs and thyroid ablative therapies, which can have a detrimental effect on pituitary mass and lead to life-threatening complications.

\section{References:-}

1. Beck-Peccoz P, Brucker-Davis F, Persani L, et al: Thyrotropin-secreting pituitary tumors. Endocrine Reviews 1996; 17: 610.

2. Beck-Peccoz P, Lania A, et al: 2013 European Thyroid Association Guidelines for the Diagnosis and Treatment of Thyrotropin-Secreting Pituitary Tumors. European Thyroid Journal 2013; 2:76-82.

3. Beck-Peccoz P, Lania A, Persani L. TSH-producing adenomas. In: Jameson JL, Degroot LJ, editors. Endocrinology. $7^{\text {th }}$ edition. USA: W.B. Saunders Publications; 2015: 266-274.

4. Maria Dabrowska A, Stanislaw Tarach J, et al: Thyroid diseases in patients with acromegaly. Archives of Medical Science 2014; 10, 4: 837-845.

5. NoriakiFukuhara, KentaroHoriguchi, et al: Short-term preoperative octreotide treatment for TSHsecreting pituitary adenoma. Endocrine Journal 2015, 62 (1), 21-27.

6. Yoenem A, Cakyr B, et al: Effect of Octreotide acetate on thyrotropin-secreting adenoma: report of two cases and review of the literature. Endocrine Regulations 1999, Vol. 33: 169-174. 